\title{
Spontaneous Fragmentations of Protonated Benzaldimines Mediated by Intermediate Ion-Neutral Complexes
}

Hans-Friedrich Grützmacher $†$ and Ursula Zalfen

Fakultät für Chemie, Universität Bielefeld, Postfach 8046, D-4802 Bielefeld, FRG

\begin{abstract}
4-Methoxymethylbenzaldimmonium ions (a) and the corresponding $N$-methylated ions (b) and $N, N$-dimethylated ions (c) were easily generated in the ion source by electron impact-induced dissociation from 1-(4methoxymethylphenyl)ethylamine and its $N$-methylated derivatives. The spontaneous fragmentations of metastable ions $a-c$ and of specifically deuterated derivatives in the second field-free region of a VG ZAB-2F mass spectrometer were studied by mass-analysed ion kinetic energy spectrometry. The formation of an amino-pquinodimethane radical cation by loss of the methoxy group is observed for all ions. In the case of $a$ and $b$ carrying at least one proton at the immonium group, competing fragmentations are the loss of $\mathrm{CH}_{2} \mathrm{O}$ and $\mathrm{CH}_{3} \mathrm{OH}$, respectively, and the formation of ions $\mathrm{CH}_{3} \mathrm{OCH}_{2}{ }^{+}, m / z 45$, and $\mathrm{C}_{7} \mathrm{H}_{7}{ }^{+}, m / z$ 91. Deuterium-labelling experiments indicated the migration of a proton from the protonated imino group of $a$ and $b$ to the aromatic ring followed by the loss of methanol from the methoxymethyl side-chain or protolysis of the bond to either side-chain to form ion-neutral complexes, in close analogy with the reactions of the corresponding protonated benzaldehydes. The intermediate ion-neutral complexes dissociate eventually by internal ion-neutral reactions resulting in the loss of $\mathrm{CH}_{2} \mathrm{O}$ and the formation of $\mathrm{C}_{7} \mathrm{H}_{7}{ }^{+}$, respectively.
\end{abstract}

\section{INTRODUCTION}

Ion-neutral complexes are now firmly established intermediates of unimolecular fragmentations of organic ions. ${ }^{1}$ These intermediates are necessary to explain the otherwise unexpected slow rates of the dissociation of some radical cations ${ }^{2}$ and also the alkane eliminations of certain metastable radical cations, contrasting the losses of alkyl radicals by $\alpha$-cleavage of energetically excited ions. ${ }^{3}$ An especially intriguing sub-class of spontaneous fragmentations of metastable ions mediated by intermediate ion-neutral complexes are rearrangement reactions including a transposition of a group of atoms within the reacting ion over large molecular distances before the fragmentation. These rearrangements can be regarded as internal ion-molecule reactions of the intermediate complex. Related internal reactions have been observed for Van der Waals clusters after photoionization. $^{4}$ In contrast to electron-transfer and protontransfer reactions, the transfer of atom groups is usually associated with a substantial critical energy, and the internal energy gained by the electrostatic attraction between the components during the formation of the encounter complex of a bimolecular ion-molecule reaction is used to surmount this critical barrier. However, in a complex arising from a bond dissociation of a precursor ion, the components are formed in close vicinity to each other. Therefore, the special features of the intermediate ion-neutral complexes of unimolecular reactions are the generation of the complex with an initial orientation of the components that is probably

† Author to whom correspondence should be addressed. very likely different from the reactive one and probably with a different internal energy compared with the encounter complex of a 'true' bimolecular ion-neutral reaction.

Recently, we have shown ${ }^{5}$ that methoxymethylsubstituted aromatic aldehydes and ketones initially protonated at the carbonyl group decompose metastably via a proton migration onto the aromatic ring. In addition to the elimination of methanol, this proton migration is followed by a protolytic bond cleavage of either side-chain to yield ion-neutral complexes (Scheme 1). The complex formed from an acyl cation and an arylmethyl methyl ether decomposes to an arylmethyl cation by elimination of an ester molecule via an internal reaction of the acyl cation with the ether group. The other complex consisting of a methoxymethyl cation and an aromatic carbonyl compound reacts by a transfer of a methyl cation, presumably to the carbonyl group, and elimination of a molecule of formaldehyde. In the case of an aromatic aldehyde as the carbonyl component, a hydride abstraction is also observed, yielding a stable acylium ion and a dimethyl ether molecule. All these internal reactions of the intermediate ion-neutral complexes were supported by specific labelling with deuterium. ${ }^{5}$ However, an MNDO calculation of the reaction energy profiles for the formation and further reactions of the intermediate ion-neutral complexes revealed that the initial proton transfer to the aromatic ring needs a substantial activation energy. As a consequence, the ring-protonated ion and the subsequently formed ion-neutral complex may arise as a chemically activated species with sufficient energy for the internal ion-neutral reactions. This excess energy may possibly be varied by selecting a protonated group at the aromatic ring different from the carbonyl group 


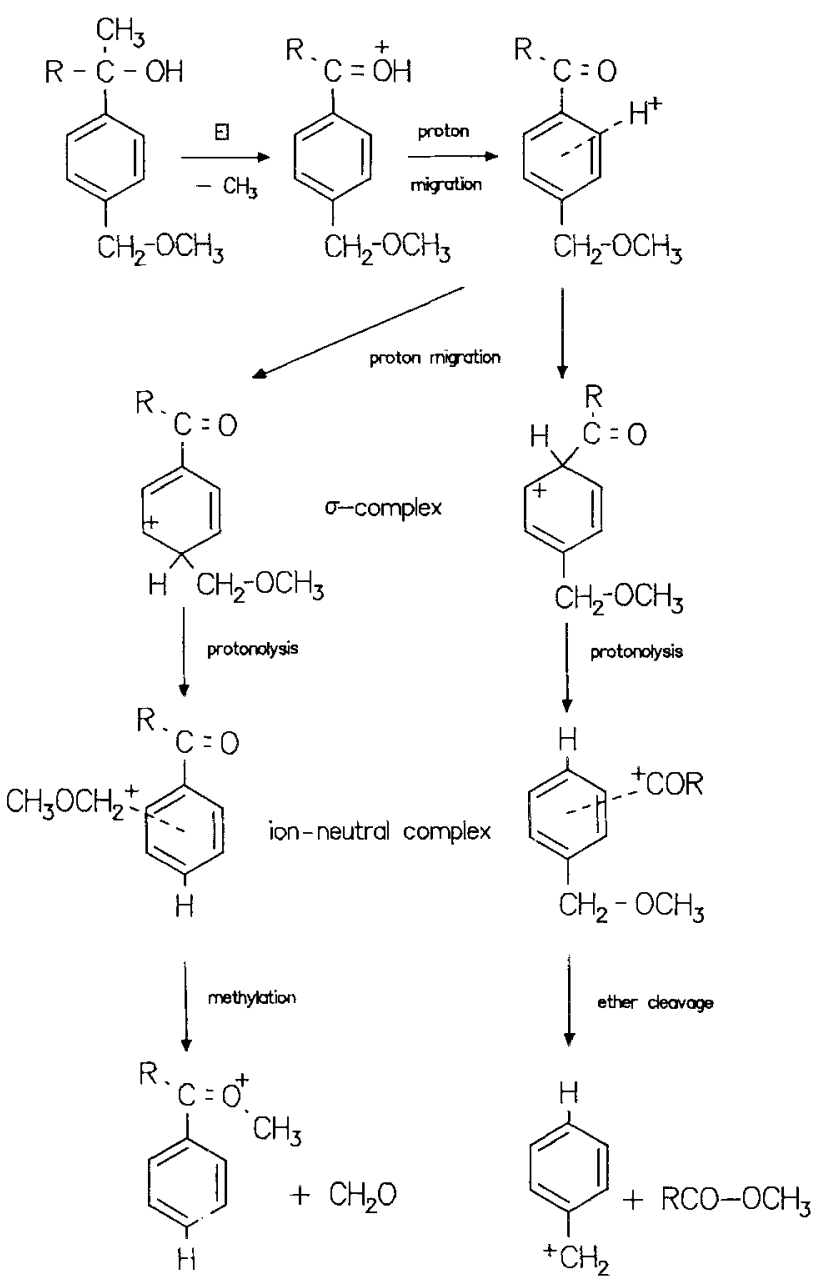

Scheme 1

as the starting point of the fragmentation process. Using this concept, we report here the results of an investigation of the fragmentations of metastable benzaldimmonium ions initially protonated at the imino group.

\section{RESULTS AND DISCUSSION}

The $p$-methoxymethylbenzaldimmonium ion $a$, the $N$ methyl-p-methoxymethylbenzaldimmonium ion $b$ and the $N, N$-dimethyl- $p$-methoxymethylbenzaldimmonium ion $c$ were generated from the molecular ions of the 1-(4-methoxymethyl)phenylethylamine, 1, and its $N$ methyl- and $N, N$-dimethyl derivatives, 2 and 3 , respectively, by $70 \mathrm{eV}$ electron impact (EI) fragmentation. Similarly, the deuterated analogues of ions $a, b$ and $c$ labelled at the immonium group, the methoxy group and the aromatic ring (Scheme 2) were prepared from the correspondingly deuterated 1 -phenylethylamines.

For every compound, the peak of the corresponding benzaldimmonium ion was the base peak of the mass spectrum and only a few other intense signals were observed (Table 1). The spontaneous fragmentations of the (metastable) benzaldimmonium ions were studied by mass-analysed ion kinetic energy (MIKE) spectrometry in the second field-free region ( 2 nd FFR) of a VG ZAB-2F mass spectrometer. The results are given in Table 2. The most important reactions are the loss of a methoxy radical and of a methanol molecule and the formation of the ions $\mathrm{C}_{7} \mathrm{H}_{7}{ }^{+}, \mathrm{m} / z 91$ and $\mathrm{CH}_{3} \mathrm{OCH}_{2}{ }^{+}$, $m / z$ 45. Additional smaller signals are observed for the

Table 1. Characteristic fragment ions in the $70 \mathrm{eV}$ mass spectra of 1-3 [rel. int. in \% base peak]

\begin{tabular}{|c|c|c|c|c|c|c|}
\hline \multirow[b]{2}{*}{ on } & \multicolumn{2}{|c|}{1} & \multicolumn{2}{|r|}{ 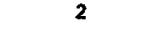 } & \multicolumn{2}{|c|}{3} \\
\hline & $m / z$ & $\% B$ & $m / z$ & $\% B$ & $m / 2$ & $\% B$ \\
\hline$M^{+\cdot}$ & 165 & 3.0 & 179 & 1.5 & 193 & 8.0 \\
\hline $\mathrm{M}-\mathrm{H} 1^{+}$ & 164 & 3.5 & 178 & 3.0 & 192 & 2.0 \\
\hline $\mathrm{M}-\mathrm{CH}_{3} 1^{+}$ & 150 & 100.0 & 164 & 100.0 & 178 & 100.0 \\
\hline $\mathrm{M}-\mathrm{OCH}_{3} \mathrm{~T}^{+}$ & 134 & 5.5 & 148 & 3.0 & 162 & 4.0 \\
\hline $\mathrm{M}-\left(\mathrm{CH}_{3}+\mathrm{CH}_{2} \mathrm{O}\right) 1^{+}$ & 120 & 22.0 & 134 & 5.0 & 148 & 13.0 \\
\hline $\mathrm{M}-\left(\mathrm{CH}_{3}+\mathrm{CH}_{3} \mathrm{O}\right) 1^{+\cdot}$ & 119 & 20.0 & 133 & 15.0 & 147 & 18.0 \\
\hline $\mathrm{C}_{7} \mathrm{H}_{7}{ }^{+}$ & 91 & 23.0 & 91 & 10.0 & 91 & 16.0 \\
\hline $\mathrm{CH}_{3} \mathrm{CH}=\mathrm{N}^{+} \mathrm{R}_{2}$ & 44 & 16.0 & 58 & 17.0 & 72 & 34.0 \\
\hline $\mathrm{CH}_{3} \mathrm{OCH}_{2}{ }^{\circ}$ & 45 & 16.0 & 45 & 12.0 & 45 & 16.0 \\
\hline
\end{tabular}

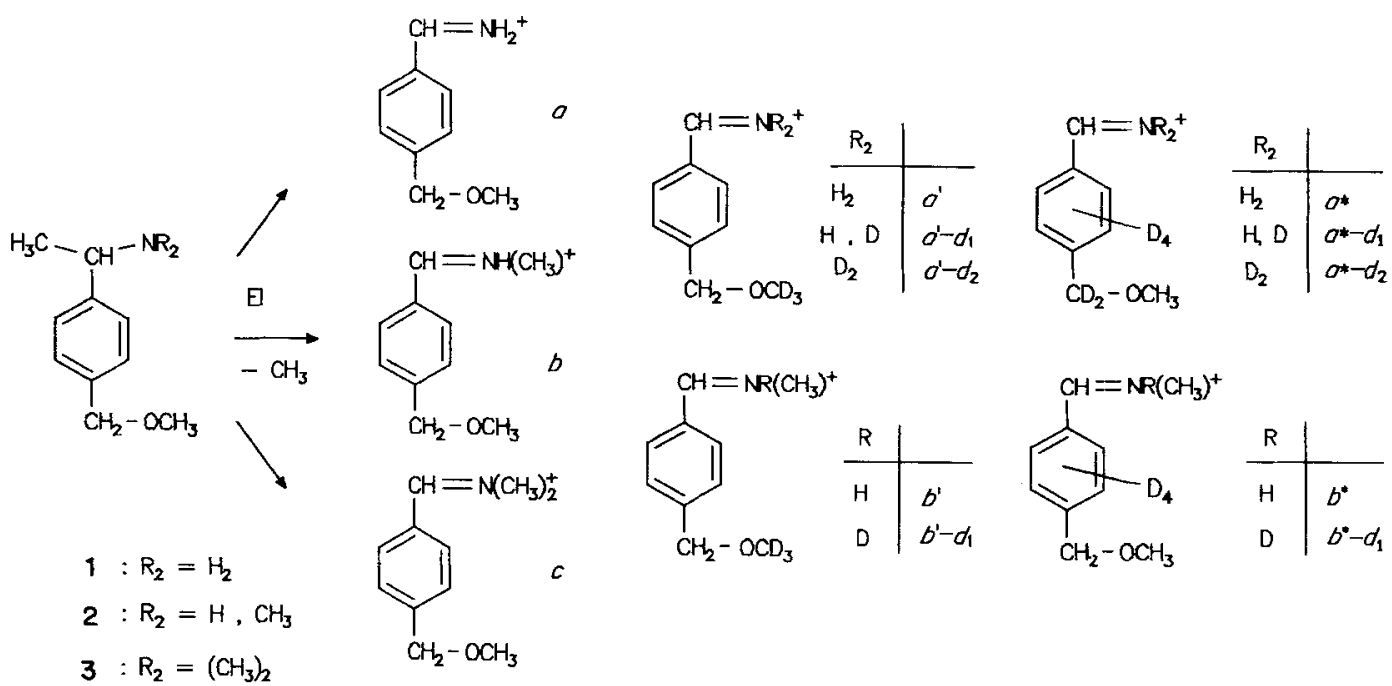


Table 2. MIKE spectra of the benzaldimmonium ions $a-c$ [rel. int. in \% total fragment ion current]

\begin{tabular}{cccccccc} 
Ion & $-\mathrm{H}$ & $-\mathrm{CH}_{3}$ & $-\mathrm{CH}_{2} \mathrm{O}$ & $-\mathrm{CH}_{3} \mathrm{O}$ & $-\mathrm{CH}_{3} \mathrm{OH}$ & $\mathrm{C}_{7} \mathrm{H}_{7}{ }^{+}$ & $\mathrm{CH}_{3} \mathrm{OCH}_{2}{ }^{+}$ \\
$a$ & 2 & 1 & 5 & 21 & 26 & 22 & 21 \\
$b$ & 5 & 13 & 7 & 28 & 10 & 14 & 14 \\
$c$ & - & 3 & - & 97 & - & - & - \\
\hline
\end{tabular}

loss of a methyl radical and for the elimination of a formaldehyde molecule.

The $N, N$-dimethylbenzaldimmonium ion $c$ does not correspond to a protonated species, and its fragmentations have to occur without a preceding proton migration. In fact, the only reaction observed besides a weak loss of a methyl group is the loss of a methoxy radical giving rise to the dimethylamino-p-quinodimethane radical cation (Scheme 3). Obviously this unusually strong loss of a radical from an even-electron ion is triggered by the stability of the quinoid radical cation substituted by an electron donor. In the case of metastable $a$ and $b$, other fragmentations can compete with the formation of the amino-p-quinodimethane radical cation.

Heats of formation $\Delta H_{\mathrm{f}}^{\circ}$ (amino-p-quinodimethane $)^{+\cdot}=908 \mathrm{~kJ} \mathrm{~mol}^{-1}$ and $\Delta H_{\mathrm{f}}^{\circ}(a)=630 \mathrm{~kJ}$ $\mathrm{mol}^{-1}$ were calculated by MNDO. ${ }^{6}$ Assuming $\mathrm{CH}_{3} \mathrm{O}^{\circ}$ (taking for the purpose of this calculation $\Delta H_{\mathrm{f}}^{\circ}=23.4$ $\mathrm{kJ} \mathrm{mol}^{-17}$ ) as the neutral fragment, a heat of reaction $\Delta H_{\mathrm{r}}=302 \mathrm{~kJ} \mathrm{~mol}^{-1}$ is obtained for this dissociation reaction of the methoxymethylbenzaldimmonium ions. $\dagger^{\dagger}$ The critical energies of the other (multi-step) fragmentations of metastable $a$ and $b$ must be equal or lower than this $\Delta H_{\mathrm{r}}$ to compete with the loss of $\mathrm{CH}_{3} \mathrm{O}^{\circ}$ by a simple bond cleavage. The pertinent thermochemical data are shown in Table 3 and Scheme 4 and, with the exception of the weak $\mathrm{CH}_{3}{ }^{\cdot}$ loss, the $\Delta H_{\mathrm{r}}$ values are positively below this limit.

The elimination of methanol from metastable $a$ and $b$ involves the hydrogen atoms at the immonium group, as demonstrated by the losses of methanol-O-d $d_{1}$ and trideuteromethanol- $O-d_{1}$ from the $N$-deuterated ions $a-d_{1}, a-d_{2}$ and $b-d_{1}$ and $a^{\prime}-d_{1}, a^{\prime}-d_{2}$ and $b^{\prime}-d_{1}$, respectively (Table 4). This can be explained by the migration of $\mathrm{H}^{+}\left(\mathrm{D}^{+}\right)$from the immonium group to the methoxy group at the opposite position of the aromatic ring. The

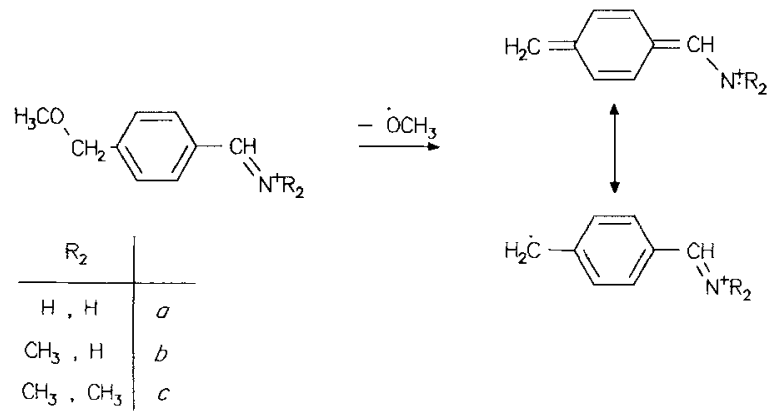

Scheme 3

† A rearrangement of the departing methoxy radical to the more stable ${ }^{\circ} \mathrm{CH}_{2} \mathrm{OH}\left(\Delta H_{\mathrm{f}}=-23.7 \mathrm{~kJ} \mathrm{~mol}^{-17}\right)$ cannot be totally excluded. In this case $\Delta H_{\mathrm{r}}=254 \mathrm{~kJ} \mathrm{~mol}^{-1}$ is obtained.
Table 3. Heats of formation of ions and neutral species (in $\mathrm{kJ}$ $\mathrm{mol}^{-1}$ ) used for the calculation of Scheme 3

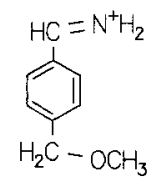

$630^{\text {a) }}$

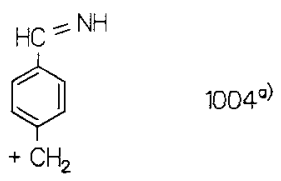

(1)

$908^{0)}$

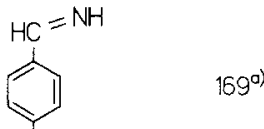

$\mathrm{HC}=\mathrm{N}^{+} \mathrm{HCH}_{3}$<smiles>Cc1ccccc1</smiles>

$804^{\circ)}$

$\mathrm{H}$

$169^{\text {a) }}$

1

$\mathrm{H}_{2} \mathrm{C}-\mathrm{OCH}_{3}$

$-94^{\circ}$

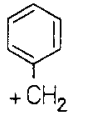

$$
911^{a)}
$$

$\mathrm{H}_{3} \mathrm{COCH}=\mathrm{NH}-130^{\text {o) }}$

$\mathrm{H}_{3} \mathrm{COH}$

$\mathrm{H}_{3} \mathrm{CO}$.

$\mathrm{H}_{3} \mathrm{COCH}_{2}^{+}$

$657^{c)}$

$\mathrm{CH}_{2} \mathrm{OH}$

$\left.23.4^{c}\right)$

$\mathrm{HC} \equiv \mathrm{NH}^{+}$

949)

$\mathrm{H}_{2} \mathrm{C}=\mathrm{O}$

$-109^{\mathrm{b})}$

${ }^{2}$ Calculated by MNDO

${ }^{\mathrm{b}}$ S. G. Lias, J. F. Liebman and R. D. Levin, J. Chem. Phys. Ref. Data $13,695(1984)$

${ }^{c}$ Ref. 7.

competition between the losses of methanol and methanol- $O-d_{1}$ from these ions as well as from the $C$ deuterated species $a^{*}$ and $b^{*}$ shows clearly an exchange between the migrating $\mathrm{H}^{+}\left(\mathrm{D}^{+}\right)$and the $\mathrm{H}(\mathrm{D})$ atoms at the ring expected for an initial $\mathrm{H}^{+}\left(\mathrm{D}^{+}\right)$transfer from

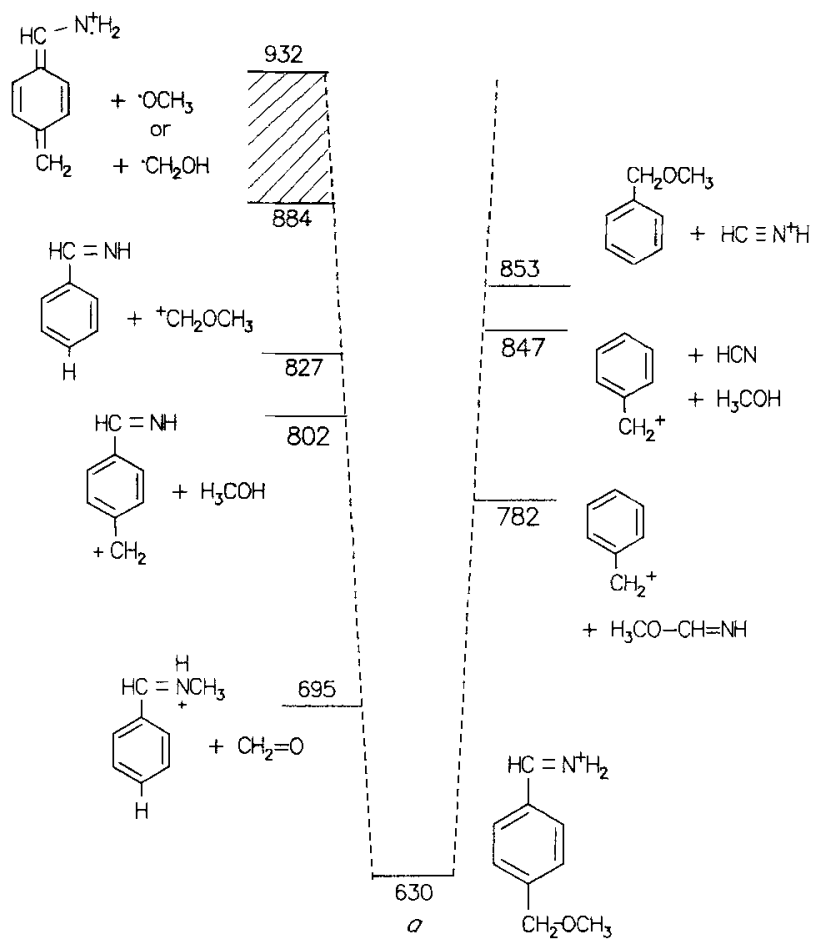

Scheme 4 
Table 4. Elimination of $\mathrm{H}_{3} \mathrm{COH}$ and $\mathrm{H}_{3} \mathrm{COD}$ from deuterated benzaldimmonium ions $a$ and $b$ (\% total methanol elimination)

\begin{tabular}{|c|c|c|c|c|c|c|c|}
\hline & $a-d$, & $a-d_{2}$ & $a^{\prime}-d_{1}$ & $a^{\prime}-d_{2}$ & $a^{*}$ & $a^{*}-d_{1}$ & $a^{*}-d_{2}$ \\
\hline \multirow{3}{*}{$\begin{array}{l}-\mathrm{H}_{3} \mathrm{COH} /-\mathrm{H}_{3} \mathrm{COD} \\
-\mathrm{D}_{3} \mathrm{COH} /-\mathrm{D}_{3} \mathrm{COD}\end{array}$} & $75: 25$ & $54: 46$ & - & - & $52: 48$ & $27: 73$ & $0: 100$ \\
\hline & - & - & $71: 29$ & $58: 42$ & - & - & - \\
\hline & $b \cdot d_{1}$ & & $b^{\prime}-d_{1}$ & & $b^{*}$ & $b^{*}-d_{1}$ & \\
\hline$-\mathrm{H}_{3} \mathrm{COH} /-\mathrm{H}_{3} \mathrm{COD}$ & $74: 26$ & & 一 & & $33: 66$ & $0: 100$ & \\
\hline$-\mathrm{D}_{3} \mathrm{COH} /-\mathrm{D}_{3} \mathrm{COD}$ & - & & $74: 26$ & & 一 & - & \\
\hline
\end{tabular}

the immonium group to the aromatic ring and a subsequent stepwise migration via $\sigma$-complexes as suggested for the protonated aromatic carbonyl compounds (Scheme 5). ${ }^{5}$

In fact, the data obtained for $H / D$ exchange of the $N$-methylbenzaldimmonium ions $b$ are very similar to those of the protonated benzaldehydes. ${ }^{5 a}$ However, the limit of a statistical exchange between the migrating $\mathrm{H}^{+}\left(\mathrm{D}^{+}\right)$and aromatic the $\mathrm{H}(\mathrm{D})$ atoms is never reached, but a preferred participation of $H(D)$ initially at the immonium group is observed. The is evident especially from the large amounts of $\mathrm{CH}_{3} \mathrm{OD}$ and $\mathrm{CD}_{3} \mathrm{OD}$ eliminated from $a-d_{2}$ and $a^{\prime}-d_{2}$ and from the preferred loss of $\mathrm{CH}_{3} \mathrm{OH}$ from $a^{*}$ (Table 4). Thus, the methanol elimination takes place via a 'specific process' involving specifically the proton(s) at the originally protonated immonium group besides the 'statistical process' of a proton migration across the aromatic ring. A similar effect has been observed for the loss of methanol from methoxymethyl-substituted aromatic carbonyl compounds initially protonated at the carbonyl group, ${ }^{5,8}$ and has been explained by a competition between proton migration via $\sigma$-complexes and via $\pi$ complexes. $^{8}$ However, in view of the increased proton affinity of the benzaldimino group, the large portion of the specific process involving $\pi$-complexes is unexpected.

The formation of the ions $\mathrm{CH}_{3} \mathrm{OCH}_{2}{ }^{+}, m / z 45$, is another consequence of the proton migration to the aromatic ring (Scheme 6) and is well known from the MIKE spectra of related ions. ${ }^{5}$ The estimation of the reaction energies (Scheme 4) shows that this process is slightly more endothermic than the elimination of methanol. Thus the final proton transfer step to the methoxy group of the ether side-chain during the methanol elimination probably needs some extra critical energy. ${ }^{8}$ The other fragmentation involving the $\mathrm{CH}_{3} \mathrm{OCH}_{2}$ sidechain is the elimination of $\mathrm{CH}_{2} \mathrm{O}$ from ions $a$ and $b$. The losses of $\mathrm{CH}_{2} \mathrm{O}$ from the trideuteromethoxy substi-

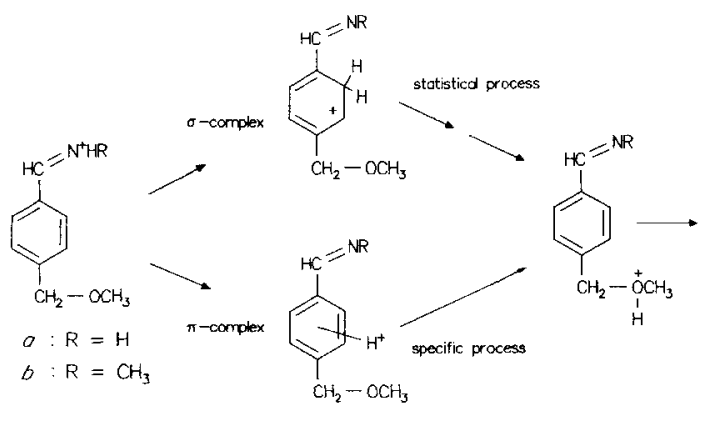

Scheme 5

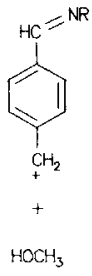

tuted ions $a^{\prime}$ and $b^{\prime}$ and the losses of $\mathrm{CD}_{2} \mathrm{O}$ from the benzylic deuterated ions $a^{*}$ and $b^{*}$ shown clearly that it is the $-\mathrm{OCH}_{2}-$ moiety of the side-chain which is eliminated. This agrees with the fragmentations of the corresponding protonated aromatic carbonyl compounds $^{5}$ and with the suggested mechanism via a methylation by the ion $\mathrm{CH}_{3} \mathrm{OCH}_{2}{ }^{+}$in an intermediate ion-neutral complex (Scheme 6). The estimation of the reaction enthalpies (Scheme 4) shows that the loss of a formaldehyde molecule is the energetically most favoured reaction of ions $a$ and $b$ and is much less endothermic than the dissociation of the complex into the free methoxymethyl cation. This assists in switching from the dissociative pathway to the internal methylation reaction of the complex.

The loss of methanol from $a$ and $b$ followed by the elimination of $\mathrm{HCN}$ and $\mathrm{CH}_{3} \mathrm{CN}$ (or $\mathrm{CNCH}_{3}$ ), respectively, formally gives rise to the ion $\mathrm{C}_{7} \mathrm{H}_{7}{ }^{+}$. However, this is not the mechanism for the formation of the ions $\mathrm{C}_{7} \mathrm{H}_{7}{ }^{+}$, as can be seen by comparing the D-label retention for the methanol loss (Table 4) and for the benzyl ion formation (Table 5). In particular, the Ds at the immonium group of the ions $b-d_{1}$ are distributed between the methanol lost and the ions formed but are completely retained in the benzyl ions. Likewise, one of the seven Ds of the ions $b^{*}-d_{1}$ is removed during the elimination of methanol, but only ions $\mathrm{C}_{7} \mathrm{D}_{7}{ }^{+}$are formed. Similar discrepancies are observed for the other
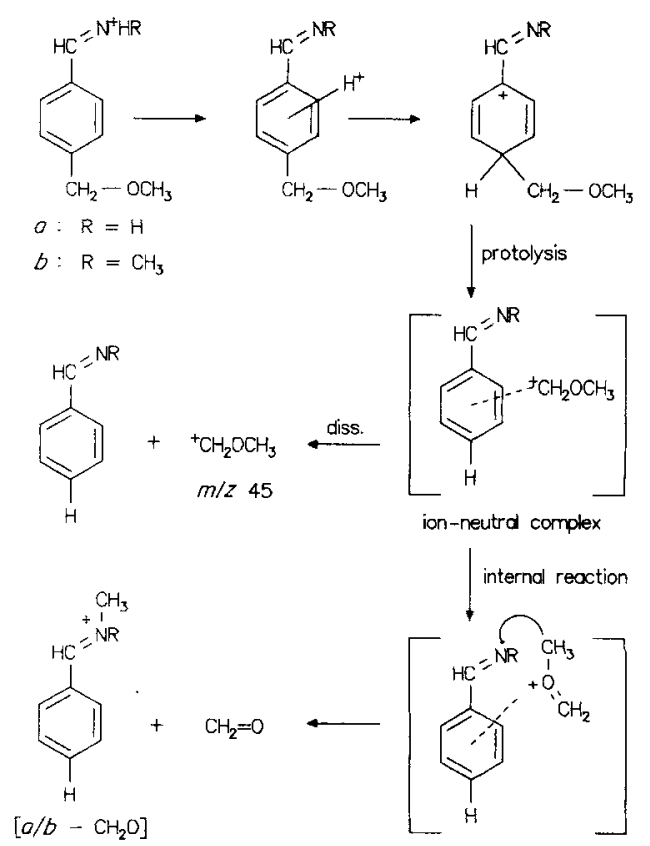

Scheme 6 
Table 5. Formation of $\mathrm{C}_{7}(\mathrm{H}, \mathrm{D})_{7}{ }^{+}$from deuterated benzaldimmonium ions $a$ and $b$ ( $\%$ total ion formation)

\begin{tabular}{lrrrrrrr} 
& $a-d_{1}$ & $a-d_{2}$ & $a^{\prime}-d_{1}$ & $a^{\prime}-d_{2}$ & $a^{*}$ & $a^{*}-d_{1}$ & $a^{*}-d_{2}$ \\
$\mathrm{C}_{7} \mathrm{H}_{7}+$ & 52 & 0 & 50 & 0 & - & - & - \\
$\mathrm{C}_{7} \mathrm{H}_{6} \mathrm{D}^{+}$ & 48 & 84 & 50 & 100 & - & - & - \\
$\mathrm{C}_{7} \mathrm{H}_{5} \mathrm{D}_{2}+$ & 0 & 16 & 0 & 0 & - & - & - \\
$\mathrm{C}_{7} \mathrm{D}_{7}^{+}$ & - & - & - & - & 0 & 29 & 100 \\
$\mathrm{C}_{7} \mathrm{HD}_{6}{ }^{+}$ & - & - & - & - & 83 & 71 & 0 \\
$\mathrm{C}_{7} \mathrm{H}_{2} \mathrm{D}_{5}{ }^{+}$ & - & - & - & - & 17 & 0 & 0 \\
& $b-d_{1}$ & & $b^{\prime} \cdot d_{1}$ & & $b^{*}$ & $b^{*}-d_{1}$ & \\
$\mathrm{C}_{7} \mathrm{H}_{7}{ }^{+}$ & 0 & & 0 & & - & - & - \\
$\mathrm{C}_{7} \mathrm{H}_{6} \mathrm{D}^{+}$ & 100 & & 100 & & - & - & \\
$\mathrm{C}_{7} \mathrm{D}_{7}{ }^{+}$ & - & & - & & 0 & 100 & \\
$\mathrm{C}_{7} \mathrm{H}_{8} \mathrm{D}^{+}$ & - & & - & & 100 & 0 & \\
\hline
\end{tabular}

deuterated ions. Therefore, in close analogy with the reactions of the corresponding carbonyl compounds, a fragmentation mechanism including an intermediate ion-neutral complex formed from the ion $\mathrm{HCNH}^{+}$and $\mathrm{HCNCH}_{3}{ }^{+}$, respectively, and a molecule benzyl methyl ether is suggested (Scheme 7).

A direct dissociation of this complex is not observed for metastable ions, although this would be less endothermic than the loss of the $\mathrm{CH}_{3} \mathrm{O}^{*}$ radical from ions $a$ and $b$, respectively (Scheme 4). Instead, the ions $\mathrm{HCNH}^{+}$and $\mathrm{HCNCH}_{3}{ }^{+}$may react as electrophiles and cleave the ether group to yield methyl formimidates in addition to the ion $\mathrm{C}_{7} \mathrm{H}_{7}{ }^{+}$. An estimation of the reaction enthalpy shows (Scheme 4) that this internal ion-molecule reaction is energetically favoured over a direct dissociation and even over the combined losses of $\mathrm{H}_{3} \mathrm{COH}$ and $\mathrm{HCN}$. In the case of the ions $a-d_{2}$ carrying two Ds at the immonium group, one observes a small amount of ions $\mathrm{C}_{7} \mathrm{H}_{5} \mathrm{D}_{2}{ }^{+}$(Table 5) in addition to the expected ions $\mathrm{C}_{7} \mathrm{H}_{6} \mathrm{D}^{+}$. Similarly, ion $a^{*}$ gives rise to some ions $\mathrm{C}_{7} \mathrm{H}_{2} \mathrm{D}_{5}{ }^{+}$. Thus, both hydrogen atoms originally at the imino- $\mathrm{N}$ may be incorporated into the ion $\mathrm{C}_{7} \mathrm{H}_{7}{ }^{+}$eventually formed at least in some cases, and the mechanism must be more complicated than shown in Scheme 7. The incorporation of both hydrogen atoms at the $\mathrm{N}$ atom of the primary immonium group can be explained by a reversible proton migration in $a$ between the imino group and the aromatic ring before the complex formation or by a reversible protonation of the aromatic ring by the acidic $\mathrm{HCNH}^{+}$ion within the complex, resulting in an exchange between the hydrogen atoms at the aromatic ring and at the $\mathrm{N}$ atom. $\mathrm{A}$ similar phenomenon, i.e. exchange of an acidic hydrogen atom of the ion with the hydrogen atoms at the aromatic ring of the neutral component of an intermediate ion-neutral complex, has been observed during the fragmentations of the protonated benzaldehydes. ${ }^{5} \mathrm{~A}$ third but less likely possibility is an irreversible protonation at the aromatic ring of the benzyl methyl ether by $\mathrm{HCNH}^{+}$in the ion-neutral complex followed by an elimination of methanol. In this case the elimination step has to be very fast because the loss of only HCN from the metastable $a$ is not observed, but nevertheless the proton originally transferred must have exchanged with the other $\mathrm{H}$ atoms at the aromatic ring to explain the label retention. However, in view of the lack of reli-

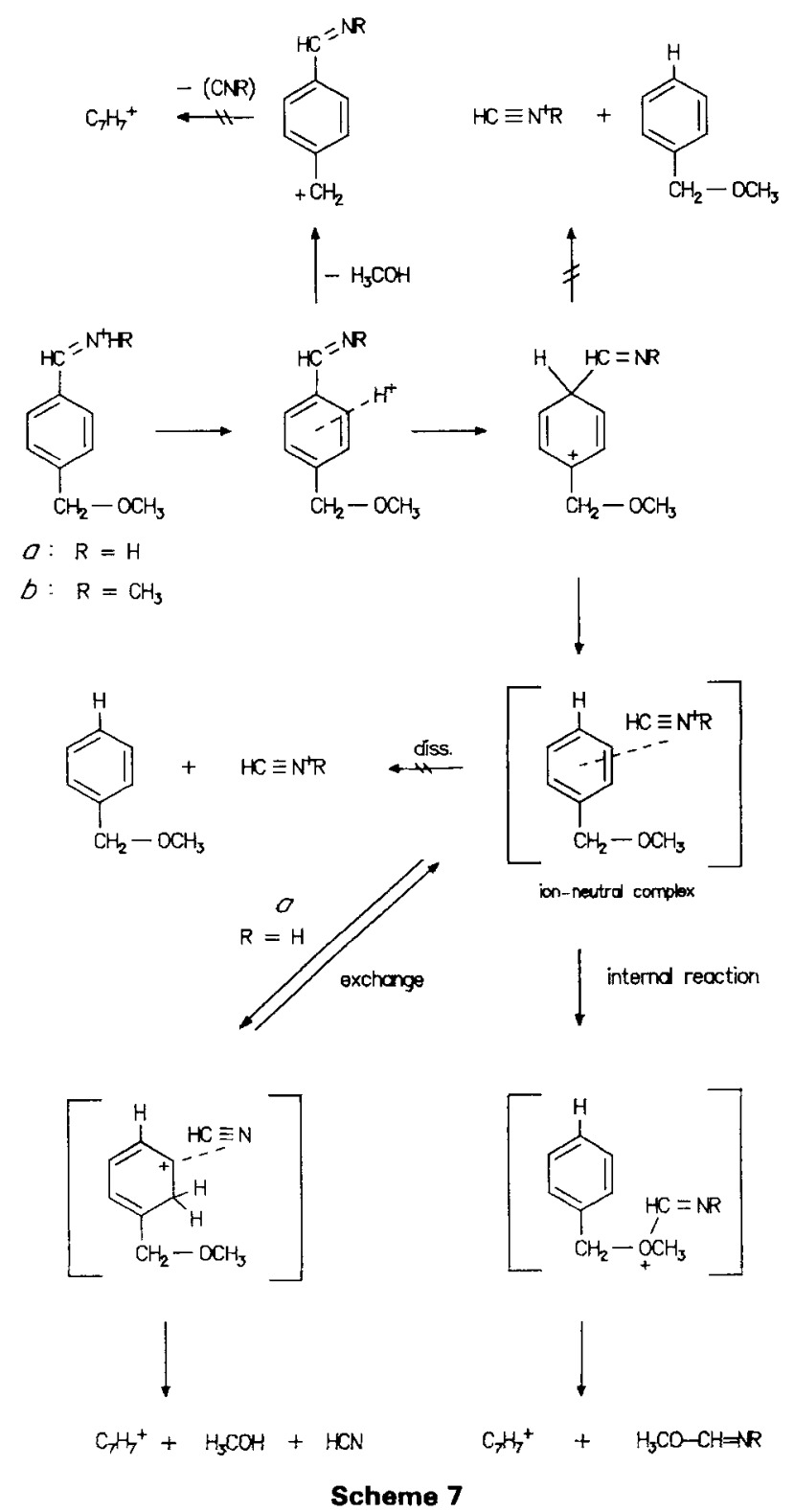

able thermochemical and kinetic data, it is not possible to exclude definitely any of these side-reactions.

\section{CONCLUSION}

This study shows that benzaldimmonium ions are conveniently prepared in the gas phase by electron impact-induced dissociation of (substituted) 1phenylethylamines. In the case of the 4-methoxymethylsubstituted benzladimmonium ions $a, b$ and $c$, the characteristic spontaneous fragmentation is the loss of a methoxy radical to produce an aminoquinodimethane radical cation. The relative intensity of this peak in the MIKE spectrum increases with increasing $N$. methylation and is the only important reaction observed for the $N, N$-dimethyl derivative $c$. In the case of ions $a$ and $b$ carrying at least one proton at the immonium group, additional reactions are observed in the MIKE spectra. The investigation of deuterated derivatives of ions $a$ and $b$ proves that these reactions 
are initiated by a proton transfer from the immonium group onto the aromatic ring, followed by the elimination of methanol, formaldehyde and methoxymethyl cations, and of the formation of ions $\mathrm{C}_{7} \mathrm{H}_{7}{ }^{+}$, respectively. Thus the benzaldimmonium ions $a$ and $b$ duplicate closely the behaviour of the correspondingly substituted protonated benzaldehydes. ${ }^{5}$ In particular, the $\mathrm{H}-\mathrm{D}$ exchange accompanying the elimination of methanol from metastable ions is similar for protonated benzaldehydes and benzaldimines in spite of the different critical energies expected for the initial proton transfer. The methoxymethyl side-chain is cleaved after the proton transfer resulting in the ions $\mathrm{CH}_{3} \mathrm{OCH}_{2}{ }^{+}$, but the formation of free ions $\mathrm{HCNH}^{+}$and $\mathrm{HCNCH}_{3}{ }^{+}$by cleavage of the other side-chain in $a$ and $b$, respectively, is not observed. Instead, the ions $\mathrm{C}_{7} \mathrm{H}_{7}{ }^{+}$arise from an intramolecular reaction at the ether group within an intermediate ion-neutral complex originating from these latter ions and a molecule of benzyl methyl ether. In addition, the elimination of $\mathrm{CH}_{2} \mathrm{O}$ is mediated by an intermediate ion-neutral complex formed during the dissociation of the ions $\mathrm{CH}_{3} \mathrm{OCH}_{2}{ }^{+}$. Thus the reactions of metastable ions $a$ and $b$ constitute additional examples for fragmentations by internal ion-neutral reactions occurring between groups isolated originally by large molecular distances. Obviously the electrostatic interaction of the ions and the dipolar neutral species of the respective dissociations is changed by the rotation of the fragments against each other, opening up new and energetically more favourable reaction channels before a complete separation of the ion and the netural species originally generated.

\section{EXPERIMENTAL}

\section{Mass spectrometry}

The EI mass spectra were measured with a MAT311A mass spectrometer using the following conditions: electron energy $70 \mathrm{eV}$, electron emitter current $2 \mathrm{~mA}$, accelerating voltage $3 \mathrm{kV}$, ion source temperature $180^{\circ} \mathrm{C}$ and sample introduction by a heated inlet system at $150^{\circ} \mathrm{C}$.
The MIKE spectra were obtained with a VG ZAB-2F mass spectrometer equipped with a combined EI-CI ion source and under the following conditions: electron energy $70 \mathrm{eV}$, electron trap current $50 \mu \mathrm{A}$, accelerating voltage $6 \mathrm{kV}$, ion source temperature $\sim 180^{\circ} \mathrm{C}$ and sample introduction by a direct inlet system with a variable leak valve at $\sim 160^{\circ} \mathrm{C}$. The ions to be studied were focused magnetically into the 2nd FFR and the spectra were recorded by scanning the electrostatic deflection field.

\section{Compounds}

All compounds used ${ }^{9}$ were refined by distillation at reduced pressure and were pure by thin-layer chromatography. Their structures were confirmed by IR and ${ }^{1} \mathrm{H}$ NMR spectroscopy.

1-(4-Methoxymethylphenyl)ethylamine (1) was obtained by the reduction of the oxime of 4-methoxymethyl acetophenone ${ }^{10}$ with $\mathrm{Na}(\mathrm{Hg})$ ethanol. $N$-Methyl-1-(4-methoxymethylphenyl)ethylamine (2) was prepared by heating methylammonium formate and 4-methoxymethylacetophenone according to Novelli. ${ }^{11}$ $N, N$-Dimethyl-1-(4-methoxymethylphenyl)ethylamine (3) was synthesized from 1 by extensive $N$-methylation with $\mathrm{CH}_{2} \mathrm{O}-\mathrm{HCOOH} .{ }^{12}$ The deuterated derivatives for the preparation of the ions $a^{\prime}$ and $b^{\prime}$, and $a^{*}$ and $b^{*}$, respectively, were prepared by the same methods but using 4-trideuteromethoxymethylacetophenone and 4methoxydideuteromethyltetradeuteroacetophenone, respectively, as the starting material. ${ }^{10}$ The exchange of the mobile $\mathrm{H}$ atoms at the amino group was performed by treating the ethylamines with $\mathrm{D}_{2} \mathrm{O}$ immediately before the introduction into the mass spectrometer. Mixtures of $N-d_{1}$ and $N-d_{2}$ compounds were obtained in the case of the primary amine 1 and its deuterated derivatives.

\section{Acknowledgements}

Financial support of this work by the Deutsche Forschungsgemeinschaft and additional support by the Fonds der Chemischen Industrie are gratefully acknowledged.

\section{REFERENCES}

1. (a) T. H. Morton, Tetrahedron 38, 3195 (1983); (b) D. J. McAdoo, Mass Spectrom. Rev. 7, 363 (1988).

2. J. D. Shao, T. Baer and D. K. Lewis, J. Phys. Chem. 92, 5123 (1988), and references cited therein.

3. (a) S. Hammerum, K. F. Donchi and P. J. Derrick, Int. J. Mass Spectrom. Ion Phys. 47, 347 (1983); (b) R. D. Bowen and D. H. Williams, J. Chem. Soc., Chem. Commun. 836 (1981); (c) S. Hammerum, J. Chem. Soc., Chem. Commun. 858 (1988); (d) S. Hammerum and H. E. Audier, J. Chem. Soc., Chem. Commun. 860 (1988); (e) J. C. Traeger, C. E. Hudson and D. J. McAdoo, Int. J. Mass Spectrom. Ion Processes 82, 101 (1988).

4. (a) J. F. Garvey and R. B. Bernstein, J. Am. Chem. Soc. 109, 1921 (1987); (b) R. Brutschy, C. Janes and J. Eggert, Ber. Bunsenges. Phys. Chem. 92, 74 (1988); (c) R. Brutschy, C. Janes and J. Eggert, Ber. Bunsenges. Phys. Chem. 92, 435 (1988); (d) S. Morgan, R. G. Keesee and A. W. Castleman, Jr, J. Am. Chem. Soc. 111, 3841 (1989).
5. (a) U. Filges and H.-F. Grützmacher, Org. Mass Spectrom. 21. 673 (1986); (b) U. Filges and H.-F. Grützmacher, Org. Mass Spectrom. 22, 444 (1987); (c) U. Filges and H.-F. Grützmacher, Int. J. Mass Spectrom. Ion Processes 83, 111 (1988); (d) H.-F. Grützmacher and G. Thielking, Org. Mass Spectrom. 23, 397 (1988).

6. W. Thiel, OCPE 4, 379 (1979).

7. J. L. Holmes and F. P. Lossing, Int. J. Mass Spectrom. Ion Processes 58, 113 (1984).

8. U. Filges and H.-F. Grützmacher, Int. J. Mass Spectrom. Ion Processes 83, 93 (1988).

9. U. Zalfen, Diplomarbeit, Universität Bielefeld (1988).

10. U. Filges, Diplomarbeit, Universität Bielefeld (1984).

11. A. Novelli, J. Am. Chem. Soc. 61, 520 (1939).

12. M. L. Moore, Org. React. 5, 301 (1949). 